\title{
Integrating Transwomen and Female Athletes with Differences of Sex Development (DSD) into Elite Competition: The FIMS 2021 Consensus Statement
}

\author{
Blair R. Hamilton ${ }^{2,3}\left(\mathbb{C}^{\circ} \cdot\right.$ Giscard Lima $^{1,4} \odot$ - James Barrett ${ }^{3} \cdot$ Leighton Seal $^{3} \cdot$ Alexander Kolliari-Turner $^{2}(1) \cdot$ \\ Guan Wang $^{65} \cdot$ Antonia Karanikolou $^{2} \cdot$ Xavier Bigard $^{5,6,7} \cdot$ Herbert Löllgen $^{6} \cdot$ Petra Zupet $^{6} \cdot$ Anca lonescu $^{6}$. \\ Andre Debruyne $^{6,7} \cdot$ Nigel Jones $^{8,9} \cdot$ Karin Vonbank $^{10} \cdot$ Federica Fagnani $^{4} \cdot$ Chiara Fossati $^{4,11}$ (1) . \\ Maurizio Casasco $^{6,7,12}$. Demitri Constantinou ${ }^{7,13} \cdot$ Bernd Wolfarth $^{7,14} \cdot$ David Niederseer $^{15}$. \\ Andrew Bosch ${ }^{16}$. Borja Muniz-Pardos ${ }^{17}$ (1) . José Antonio Casajus ${ }^{17}$ (1) . Christian Schneider ${ }^{7,18}$. \\ Sigmund Loland ${ }^{19}$ (1) - Michele Verroken ${ }^{20,21}$ (1) . Pedro Manonelles Marqueta ${ }^{7,22}$. Francisco Arroyo ${ }^{7,23}$ (1) \\ André Pedrinelli ${ }^{7,24} \cdot$ Konstantinos Natsis ${ }^{6,7,25,26}$ (D) . Evert Verhagen ${ }^{27}$. William O. Roberts ${ }^{7,28}$ (1) \\ José Kawazoe Lazzoli ${ }^{7,29} \cdot$ Rogerio Friedman $^{30}$ - Ali Erdogan ${ }^{7,31}$. Ana V. Cintron ${ }^{7,32}$. Shu-Hang Patrick Yung ${ }^{7,33}$. \\ Dina C. Janse van Rensburg ${ }^{34}$. Dimakatso A. Ramagole ${ }^{34}$. Sandra Rozenstoka ${ }^{6,7,35}$. Felix Drummond ${ }^{6,7,36}$. \\ Theodora Papadopoulou ${ }^{6,7,37}$. Paulette Y. O. Kumi ${ }^{38}$. Richard Twycross-Lewis ${ }^{39}$ (1) Joanna Harper ${ }^{40}$. \\ Vasileios Skiadas ${ }^{41}$. Jonathan Shurlock ${ }^{42} \cdot$ Kumpei Tanisawa $^{43}$. Jane Seto ${ }^{44,45} \cdot$ Kathryn North ${ }^{44,45}$. \\ Siddhartha S. Angadi ${ }^{46}$. Maria Jose Martinez-Patiño $0^{47}$. Mats Borjesson ${ }^{7,48,49} \cdot$ Luigi Di Luigi $^{7,50}$. \\ Michiko Dohi ${ }^{7,51}$. Jeroen Swart7,52 . James Lee John Bilzon ${ }^{7,53}$ (1) - Victoriya Badtieva ${ }^{7,54,55}$ (I) Irina Zelenkova ${ }^{17}$. \\ Juergen M. Steinacker ${ }^{6,7,56}$ (D) Norbert Bachl $^{6,7,57,58} \cdot$ Fabio Pigozzi $^{4,6,7,11}$ (1) $\cdot$ Michael Geistlinger ${ }^{7,59}$. \\ Dimitrios G. Goulis ${ }^{60}$ (1) Fergus Guppy ${ }^{2,61}$ (1) Nick Webborn ${ }^{62}$ - Bulent O. Yildiz ${ }^{63}$ (1) $\cdot$ Mike Miller $^{64}$. \\ Patrick Singleton $^{64} \cdot$ Yannis P. Pitsiladis ${ }^{1,2,4,6,7}$ [D
}

Accepted: 10 March 2021 / Published online: 24 March 2021

(c) The Author(s), under exclusive licence to Springer Nature Switzerland AG 2021, corrected publication 2021

\begin{abstract}
Sport is historically designated by the binary categorization of male and female that conflicts with modern society. Sport's governing bodies should consider reviewing rules determining the eligibility of athletes in the female category as there may be lasting advantages of previously high testosterone concentrations for transwomen athletes and currently high testosterone concentrations in differences in sex development (DSD) athletes. The use of serum testosterone concentrations to regulate the inclusion of such athletes into the elite female category is currently the objective biomarker that is supported by most available scientific literature, but it has limitations due to the lack of sports performance data before, during or after testosterone suppression. Innovative research studies are needed to identify other biomarkers of testosterone sensitivity/responsiveness, including molecular tools to determine the functional status of androgen receptors. The scientific community also needs to conduct longitudinal studies with specific control groups to generate the biological and sports performance data for individual sports to inform the fair inclusion or exclusion of these athletes. Eligibility of each athlete to a sport-specific policy needs to be based on peer-reviewed scientific evidence made available to policymakers from all scientific communities. However, even the most evidence-based regulations are unlikely to eliminate all differences in performance between cisgender women with and without DSD and transwomen athletes. Any remaining advantage held by transwomen or DSD women could be considered as part of the athlete's unique makeup.
\end{abstract}

\section{Introduction}

Since antiquity, athletic and Olympic competitions have been separated according to the traditional binary concept of male/female to promote fairness and equity, as well as being divided by criteria such as weight, age, affiliation,

Extended author information available on the last page of the article 


\section{Key Points}

The use of testosterone concentration limits of $5 \mathrm{nmol} / \mathrm{L}$ in transwomen and DSD women athletes is a justifiable threshold based on the best available scientific evidence.

There is a distinct lack of sports performance data to inform and update sports policy for DSD women and transwomen athletes.

Fair integration or exclusion of transwomen and DSD women athletes needs to be based on peer-reviewed experimental sporting performance evidence when such evidence becomes available.

amateur or professional status, and level of competition [1]. The binary classification of male and female was based on different methods, including physical examination (1966), Barr bodies (1968), Y chromosome (1991), and sex-determining region Y (SRY) gene (1996) [2]. A female athlete, when suspected to be male, could have been classified as either male or female depending on the previous methodology applied. For example, an individual with androgen insensitivity syndrome, with a 46, XY karyotype, would be classified as a female in 1966 and as a male in 1968, whereas an individual with congenital adrenal hyperplasia with a 46, XX karyotype, would be classified as male in 1966 and as a female in 1968. These examples illustrate such methods were unreliable, discriminatory, not fit for purpose, and that the integration of athletes outside of the binary of male and female is not a new problem (Table 1).

Integrating athletes who previously experienced male puberty into elite female sport is far from straight forward and remains highly contentious. For this reason, the concept of "athletic gender" was recently proposed [3, 4] which involves designating athletes to a gender for sports performance only and not social identity using quantitative criteria based on performance [3]. This concept speaks to a "start over" notion put forward by Maayan Sudai [5], who proposes the introduction of a classification system based on physiological parameters for athletes, regardless of gender. This would be analogous to the classification system used to assess eligibility to compete in Paralympic events [5]; however, the application of this would be very difficult for

Table 1 Summary of what is already known in this area, and future considerations in integrating transwomen and DSD women into elite women's sport

\begin{tabular}{|c|c|}
\hline What is already known & Future considerations \\
\hline $\begin{array}{l}\text { The binary classification of athletes fails to consider differences in sex } \\
\text { development (DSD) women and transwomen athletes } \\
\text { Testosterone production and action are the primary factors used in } \\
\text { determining differences in performance between cis men and cis } \\
\text { women } \\
\text { Only observational data showing the sporting performance of trans- } \\
\text { women and DSD athletes exist } \\
\text { Recent additions in the scientific literature including original stud- } \\
\text { ies provide the necessary impetus for the development of more } \\
\text { evidence-based integration of DSD women and transwomen into } \\
\text { elite competition }\end{array}$ & $\begin{array}{l}\text { The use of testosterone concentration limits of } 5 \mathrm{nmol} / \mathrm{L} \text { in transwomen } \\
\text { and DSD women athletes is a justifiable threshold. This level could } \\
\text { be refined for specific events with the emergence of new supporting } \\
\text { evidence } \\
\text { Any treatment is a purely personal and private decision and no sports } \\
\text { body should provide recommendations on treatment } \\
\text { Fair integration of transwomen and DSD women athletes into elite sport } \\
\text { needs to be based on peer-reviewed experimental evidence } \\
\text { Any safety risks to cisgender female athletes due to the inclusion of } \\
\text { transwomen in female elite sport must be evidence-based to justify } \\
\text { exclusion } \\
\text { The assumption that the physiology of elite DSD women and trans- } \\
\text { women athletes is the same as elite male athletes is an oversimplified } \\
\text { view } \\
\text { New innovative scientific approaches are needed to guide new sports- } \\
\text { specific policy (e.g., quantifying bioactive testosterone and individual } \\
\text { sensitivity to testosterone, the role of sex chromosomes in athletic } \\
\text { performance, and the extent to which muscle memory is retained after } \\
\text { prolonged high testosterone exposure) } \\
\text { There is a distinct lack of sports performance data to inform and update } \\
\text { sports policy, in part due to the lack of funding and lack of elite ath- } \\
\text { letic participants in this research area } \\
\text { The participation of transwomen and DSD women elite athletes in } \\
\text { research will be hindered by their low numbers in elite competition. } \\
\text { Recruitment for research may have to be targeted also at the sub-elite } \\
\text { level with the specific requirement of being an athlete at higher than } \\
\text { grassroots level } \\
\text { The need to develop approaches to distinguish between predisposition } \\
\text { to outstanding performances (e.g., haematological and anatomical fea- } \\
\text { tures) and any unfair advantages held by transwomen or DSD women }\end{array}$ \\
\hline
\end{tabular}


sport's governing bodies due to its complexity and financial commitment to implement at all levels of sport.

The concept of athletic gender could help safeguard fair competition and prevent an unfair advantage, principles which underpin the true essence of sport [6], and would be in line with the fundamental principles of the Olympic Charter which emphasizes the need to respect the freedom and rights of athletes, as well as the importance of competing without any form of discrimination. The Olympic Charter states that "The enjoyment of the rights and freedoms set forth in this Olympic Charter shall be secured without discrimination of any kind, such as race, colour, sex, sexual orientation, language, religion, political or other opinion, national or social origin, property, birth or other status" [7] and importantly refers to sex and not gender. Sex is considered in Olympic sports only when it could determine the outcome of a competition. Some sports do not use a sex classification, e.g. shooting, sailing, or horse riding.

The terms "sex" and "gender" have different meanings and their overlap is conceptually complex. Sex refers to any individual's biology, such as anatomical or chromosomal differences, which are used to categorize an individual as male or female, whereas gender refers to socially constructed roles related to sex distinctions [8]. While gender identity is a self-defined social construct that shapes how an individual chooses to live, gender identity alone will not be enough to determine the appropriate sports category for each individual that allows fair competition, especially in the case of elite sport.

The current article aims to highlight the main issues to be considered surrounding the participation of female athletes with previously high testosterone concentrations (transwomen) and female athletes with naturally high testosterone concentrations [differences in sex development (DSD)] in elite female sport. The two cases, cisgender women athletes with DSD (DSD women, for short) and transwomen athletes, will be presented separately to enhance reader understanding, while future research considerations will be discussed together in Sect. 5, because the considerations for both groups of athletes are similar. It is important to note that the fluidity of gender identity does include non-binary and transmen athletes. However, in this article, the authors wish to focus on the integration of DSD women and transwomen athletes into the elite female category of sports. The reasoning for this is that transmen (birth-assigned female transitioned to male) athletes are perceived to not have the same magnitude of competitive advantage as transwomen or DSD women athletes when integrated into male elite sports [9] and that non-binary individuals are less likely to undertake gender-affirming treatment and are predominantly female sex assigned at birth [10], forgoing the effects of male puberty.

\section{Methods}

Here, we present the International Federation of Sports Medicine (FIMS) consensus on integrating DSD women and transwomen athletes into elite female sport based on identifying, selecting, and critically appraising the very limited relevant primary research. An added objective of this consensus was to provide a roadmap for future research direction. The review of the evidence was performed by the first and second author (BH and GL) using the following keywords: "transgender" or "transwomen", "intersex" or "DSD", "gender identity", "testosterone", "competition", and "sport". The first draft of the manuscript was written by the first and last authors (BH and YP). Of all 78 invited authors, 1 author declined the invitation and 7 authors elected to withdraw their names during one of the draft rounds. These names are not included on the authorship list above. All remaining 70 authors reviewed, commented on and approved the final draft. The drafting of the consensus statement was initiated by the last author (YP) via email for ease of verification and process during the unprecedented constraints due to the COVID-19 pandemic. Voting on the consensus statements was performed remotely using Google Forms (Google ${ }^{\mathrm{TM}}$, California, USA). The voting result was collated by the first author (BH) along with dissenting opinions and discussions which were manifested and reported in the manuscript. All statements received unanimous approval by all named authors except for the statement on the testosterone limit of $5 \mathrm{nmol} / \mathrm{L}$, which received majority approval and the voting result is included in the article. The authors consider it essential to declare the extent of agreement, as well as dissenting views.

\section{DSD Women Athletes}

\subsection{Background}

DSD is a group of rare conditions involving genes, hormones and reproductive organs $[11,12]$. This article will focus on the integration of DSD women athletes in the elite female category of sports who currently have high testosterone concentrations which the binary classification of sports fails to consider. The German Federal Parliament approved a law that came into effect in December 2018 that permits children with DSD born with ambiguous sexual anatomy who are not distinctly male or female to indicate a third gender category on their birth certificate [13]. This action follows a court ruling by the Federal Constitutional Court of Germany in October 2017 that ruled the existing regulations discriminated against people with DSD, the principle being that the gender identity of an individual must be protected as a fundamental human right [14]. 
The views of the Court of Arbitration for Sport (CAS) have evolved concerning legal sex being a factor to determine the eligibility of an athlete to compete in a male or female category. In the Dutee Chand vs. the Athletics Federation of India and the International Association of Athletics Federations (IAAF) arbitration tribunal in 2014, CAS stated in their decision that "The distinction between male and female is a matter of legal recognition" [15]. In contrast, in the Caster Semenya and Athletics South Africa vs. IAAF tribunal in 2018, CAS stated that "a person's legal sex alone may not always constitute a fair and effective means of making that determination" [16]. The Human Rights Council under the United Nations recently released a statement on discrimination against women in sport [17]. While not limited to discrimination concerning DSD women and androgen sensitivity, the position taken is that both member and non-member states of the United Nations should work in unison to recognize protected characteristics and eliminate discrimination.

\subsection{The Challenge}

Conditions such as DSD are rare and primarily of genetic origin [18] and are presented concomitantly with ambiguous genitalia at birth which can occur phenotypically in undervirilized genotypic males or virilized genotypic females. These features can result in individuals assigned female at birth possessing testosterone concentrations comparable to cisgender males and, therefore, much higher than non-DSD women, including those with polycystic ovary syndrome [19]. Hyperandrogenic 46, XY DSD female athletes in the 2011 IAAF World Championships were 140 times more prevalent $(0.7 \%$ of athletes had testosterone concentrations of $>15.6 \mathrm{nmol} / \mathrm{L}$ [20]) compared to $0.005 \%$ [20, 21] reported in the general population [22,23], which could be an indicator of performance advantage [20]. A possible indicator of fair integration of DSD women athletes into competitive sport would be a similar prevalence of DSD women and non-DSD women athletes in the championships as in the general population.

The DSD condition is a natural attribute as opposed to a doping issue, such as the misuse of anabolic steroids. However, observational data have shown a clear difference in performance in DSD women athletes depending on whether testosterone concentrations were suppressed or not. For example, there was an average performance reduction of approximately $5.7 \%$ in the best performances of three female distance runners who had their testosterone concentrations suppressed from $21-25$ to $2 \mathrm{nmol} / \mathrm{L}$ over 2 years [23]. Although a notable finding, no firm conclusions can be reached due to the reliance on a small number of athletes. Within DSD women athletes, there are individuals with 46, XY karyotype, and androgen insensitivity, which can be either complete androgen insensitivity (CAIS) or partial androgen insensitivity (PAIS). Therefore, testosterone concentrations in such individuals will not have the same functional effect as those with normal androgen receptors. This complexity needs to be considered if testosterone concentration, either as a single parameter or more likely as one of several parameters, will evolve into a viable solution.

\subsection{The Present Rulings in Elite Sport}

Following an observational study by Bermon and Garnier describing the serum androgen levels of male and female athletes and their relationship to performance in track and field events [24], the eligibility regulations for the female classification were created and published by the IAAF (now World Athletics) in April 2018. Implementation of the policy was planned for November 2018 [25]. However, this study [24] and the subsequent regulations have been subject to much debate [26-30]. The IAAF regulations permitted female athletes with specific DSD's (i.e., testosterone concentrations $\geq 5 \mathrm{nmol} / \mathrm{L}$ and sufficient sensitivity to androgens) to compete in international competitions in the female category from 400 up to $1500 \mathrm{~m}$ if they reduced testosterone concentrations to $<5 \mathrm{nmol} / \mathrm{L}$ for at least 6 continuous months. These requirements needed to be maintained for the athlete to continue to be eligible for the female category of the events described in the regulation.

Considering a challenge brought by Caster Semenya against these regulations, the IAAF agreed to delay the implementation and await the decision from CAS. The panel's decision was released in May 2019, with the statement that the "Panel has dismissed the requests for arbitration considering that the Claimants were unable to establish that the DSD Regulations were invalid" [31]. Semenya appealed to Switzerland's Federal Supreme Court, which suspended the implementation of the eligibility regulation in June 2019. However, Semenya ultimately lost her appeal [32] in August 2020 and the eligibility regulations were reinstated with the court citing that "fairness in sport is a legitimate concern and forms a central principle of sporting competition" [33].

In addition to the media frenzy both for and against the inclusion of DSD women athletes in the female category of sports [34], editorials have been published sparking subsequent critiques and rebuttals in response [32, 35]. This fervour has also sparked academic and general community outrage at the IAAF ruling, which has been declared as discriminatory against Semenya. Idiosyncratically, the emotional and legal argument is that Semenya is being victimized and unfairly treated as a female athlete, yet her sex is not biologically clearly defined in the male/female binary definition. This case is an inevitable consequence of the antithesis between the binary concept of gender applied to 
sport and the new realm of gender fluidity, as illustrated by DSD women athletes.

World Athletics in their most recent version of the eligibility regulations for the female classification (athletes with DSD), state that not all DSD women athletes who wish to compete in the female classification should need to reduce their testosterone levels to $<5 \mathrm{nmol} / \mathrm{L}$. They state that: " $A$ woman who has androgen insensitivity syndrome (AIS) is completely (CAIS) or partially (PAIS) insensitive to testosterone, thereby eliminating (CAIS) or reducing (PAIS) the physiological effect of that testosterone. An athlete with CAIS is not a Relevant Athlete. An athlete with PAIS will only be a Relevant Athlete if she is sufficiently androgensensitive for her elevated testosterone concentrations to have a material androgenising effect. The benefit of any doubt on this issue will be resolved in favour of the athlete" [31].

\section{Transwomen Athletes}

\subsection{Background}

Transgender refers to a gender expression that is different from the sex that is assigned at birth. In this article, a specific focus will be placed on transwomen, assigned male at birth who have transitioned to female both socially and legally and have had previous exposure to high testosterone concentrations during puberty. Recently, a controversial bill (i.e., 2019 Tennessee SB2077) prohibiting the participation of transwomen athletes in school sports was introduced in the U.S. legislature. Should this bill pass into law, a burden would be placed on education providers to ensure pupils participate according to the biological sex indicated on their birth certificate. Additionally, the bill seeks to impose a civil penalty of US $\$ 10,000$ as well as the revocation of public funds for any school that acts contrary to the bill [36].

In March 2020, a second similarly controversial bill (i.e., the 2020 State of Idaho HB500) known as the "Fairness in Women's Sports Act", was passed into state law making Idaho the first state to ban transwomen from participating in girls and women's sports [37]. The bill states that "Athletic teams or sports designated for females, women, or girls shall not be open to students of the male sex" [38] and that if a student's sex is disputed, "a student may establish sex by presenting a signed physician's statement that shall indicate the student's sex solely on: (a) the student's internal and external reproductive anatomy; (b) the student's normal endogenously produced levels of testosterone; and (c) an analysis of the student's genetic makeup" [38].

The bill received praise from the Senior Vice President of U.S. Legal Division, citing that "Allowing males to compete in girls' sports destroys fair competition and women's athletic opportunities" [39] but has drawn criticism given the Act conflicts with the right to privacy provision within the 4th Amendment to the American Constitution. Indeed, this has formed the basis of a claim brought by the American Civil Liberties Union against the State of Idaho regarding the legitimacy of the Act [40], alleging that the legislation could violate the federal law known as Title IX which prohibits sex discrimination, not gender discrimination, in educational institutions that receive federal financing [41]. This kind of legislation will inevitably result in tension between domestic law and international treaties developed to promote inclusivity and protect individuals from discrimination based on protected characteristics.

\subsection{The Challenge}

Although permitted by the IOC since 2004, no recognized transgender athlete has participated in the Olympic Games [42]. The main argument opposing the integration of transwomen athletes into the female category for future Olympics is the perceived sporting advantages that transwomen have over cisgender women, such as lever length or height advantages conferred by skeletal size and bone density despite testosterone reductions [43]. Prior athletic training with high testosterone concentrations may potentially result in advantages such as muscle memory [44], which may persist for some time post testosterone suppression. This is a concern for sports highly dependent on muscle mass, strength, and aerobic capacity. This will be expanded on in Sect. 5.5.

Despite these concerns, evidence on transwomen's sporting performance is scarce (Table 1) and in the case of aerobic performance, non-existent. Couple this with the data already showing that oxygen-carrying haemoglobin levels are reduced in transwomen to female norms levels [45], it is a sports performance proxy that is urgently needing investigation due to the importance of the cardiovascular system during aerobic exercise. Low testosterone concentrations have been reported in transwomen undergoing hormone replacement therapy (HRT) [46] and in a recent meta-analysis, HRT was found not to affect the motor coordination or visuospatial abilities of transwomen [47]. In a study of 50 non-athlete transwomen who had undergone gender-affirming surgery (GAS) coupled with HRT, a reduction in muscle mass and bone mineral density was reported together with an increase in fat mass following HRT initially and 1 year after GAS [48]. These data on non-athletic transwomen and non-sports performance measures make it difficult to suggest that the athletic capabilities of transwomen individuals undergoing HRT or GAS are comparable to those of cisgender women and because of this, the recording of data describing transwomen's sporting performance should be of the highest importance to sporting governing bodies and researchers. 
While data on transwomen's athletic performance remain to be experimentally determined, a first retrospective study did evaluate the performances of eight non-elite transwoman masters athletes who had participated in running competitions, first as males and then as females [49]. Running performance was compared using a standard age grading methodology [age grade $(\%)=$ age standard $\times 100 /$ race time] for comparing groups of athletes of any age and gender in track-and-field and distance running [49, 50]. Overall, the group of athletes obtained similar "age-graded" scores in both categories. However, the design of the study may limit its relevance given the small sample size, no reporting of testosterone levels, self-reported run times, no reporting of when the participants ran after their transition, the athletes were not elite, and the findings of this study have not been replicated.

A review paper by Hilton and Lundberg [43] addressed the integration of transwomen in the elite female category of sport. The authors concluded that anthropometric and muscle mass advantages are sustained in transwomen after 12 months of gender-affirming treatment based on studies showing the physiological changes caused by HRT in transwomen and chemical castration in men. Conversely, due to these studies being conducted in non-athletic transgender women, they also concluded that "it is still uncertain how transgender women athletes, perhaps undergoing advanced training regimens to counteract the muscle loss during the therapy, would respond' [43].

Despite the lack of direct sport-specific studies of transgender athletes in their review, Hilton and Lundberg raised safety as their primary concern and proposed that 12 months of testosterone suppression is insufficient to mitigate their safety concerns [43]. However, the main criticism of this review is the purely biological argument from an elite male versus elite female position, implying that transwomen athletes are the same as elite male athletes (Table 1). Data showing lower baseline isometric torque and muscle volume [51] in transwomen compared to cisgender males highlight the problematic nature of inferring that transwomen and cisgender males are the same, as this ignores the impact of gender-affirming treatments such as HRT and GAS and the psychological effects of gender dysphoria such as low selfesteem, anxiety and/or depression, and becoming socially isolated [52].

Recently, Roberts et al. [53], retrospectively reviewed pre- and post-HRT military fitness test results in transwomen individuals $(n=46)$ of the U.S. Air Force. These authors found that the push-up ( $31 \%$ more than their female counterparts) and sit-up (15\% more than their female counterparts) advantages over ciswomen at baseline had been negated after 2 years, but not after 1 year. This finding agrees with previous studies that have shown that baseline muscular strength in transwomen is not significantly diminished after
1 year [51,53] but is after 2 years of HRT [53]. Roberts et al. also found that running performance in the 1.5 mile run remained $12 \%$ faster on average in transwomen after 2 years of HRT [53]. These findings require replication in trained transwomen athletes, although they would suggest a different rate and extent of mitigation of the advantages held by transwomen given that the strength advantages, but not the cardiovascular advantages, of transwomen were mitigated after 2 years of HRT. These observations also question the required testosterone suppression time of 12 months for transwomen to be eligible to compete in women's sport, as most advantages over ciswomen were not negated after 12 months of HRT. How applicable these performance data are from both Harper [49] and Roberts et al. [53] in determining the extent of advantage remaining in transwomen athletes post-gender-affirming treatment remains to be determined. This will require longitudinal transgender athlete case-comparison studies that control for variations in hormonal exposure and involve numerous indices of performance (Table 1).

\subsection{The Present Rulings in Elite Sport}

The participation of transgender athletes in the Olympic Games was approved following the 2003 Stockholm Consensus on Sex Reassignment in Sports, which recommended that transwomen athletes undergoing sex reassignment after puberty be eligible for competition 2 years post-gonadectomy, HRT, and legal recognition of assigned sex [42]. The IOC released one update of the recommendations in 2015 [54]. Most sports governing bodies adopted this policy, declaring the eligibility of transwomen athletes with serum testosterone concentrations $<10 \mathrm{nmol} / \mathrm{L}$ for at least 12 months before the first competition and throughout the competition period. There was also no requirement for surgical procedures for any anatomical changes. World Athletics [55], World Rowing [56] and Union Cycliste Internationale (UCI) [57] have all adopted the lower serum testosterone concentration limit of $5 \mathrm{nmol} / \mathrm{L}$ for transwomen athletes. Some would consider a $5 \mathrm{nmol} / \mathrm{L}$ limit high, as healthy premenopausal women typically have a testosterone concentration $<5 \mathrm{nmol} / \mathrm{L}$ (e.g., $<1.7 \mathrm{nmol} / \mathrm{L}$ ) [19]). The support for the $<5 \mathrm{nmol} / \mathrm{L}$ limit (Table 1) for transwomen athletes emerges from a study where 24 healthy, physically active women aged $18-35$ years underwent 10 weeks of testosterone treatment [22]. This study reported improved running time to exhaustion during an incremental maximal test on a treadmill by $21.17 \mathrm{~s}(8.5 \%)$ and an increase in lean body mass. However, the average testosterone concentrations of these participants did not exceed $5 \mathrm{nmol} / \mathrm{L}$ (from $0.9 \pm 0.4$ to $4.3 \pm 2.8 \mathrm{nmol} / \mathrm{L}$ ) [22], which is considerably below the $10 \mathrm{nmol} / \mathrm{L}$ threshold used by the IOC [54]. 
World Rugby became the first international sports governing body to ban the participation of transwomen in the elite female level of sport in October 2020. They state that "Transgender women may not currently play women's rugby because of the size, force- and power producing advantages conferred by testosterone during puberty and adolescence, and the resultant player welfare risks this creates" [58]. The policy, by its admission, is based on a "hypothetical cross-over scenario in which a typical male tackler mass is involved in a tackle against a ball carrier with a typical female mass" [58]. The policy itself speaks to the "common sense" view that transwomen athletes are larger and stronger than their cisgender peers, which mischaracterises transwomen athletes as elite male athletes (Table 1) and has been opposed by rugby unions such as the USA and Canada. England Rugby will also not implement the policy stating to the media that it "believes further scientific evidence is required alongside detailed consideration of less restrictive measures in relation to the eligibility of transgender players" [59]. World Rugby's ruling is a prominent polarising example of the need for sports-specific performance data for transwomen athletes.

\section{Future Research Considerations}

\subsection{Testosterone as the Primary Biomarker for Eligibility}

Despite being imperfect, serum testosterone concentrations are being considered as the primary biomarker to regulate the inclusion of athletes into the female category. At this time, it is the only method based on an objective biomarker supported by most available scientific literature (Table 1), while also accomplishing the integration of DSD women athletes and transwomen athletes into the female category of sports. This is consistent with the fundamental principles of the Olympic Charter and is an attempt to be fair to all participants by ensuring an equitable competitive environment. However, many unresolved issues need clarification before unreservedly adopting testosterone concentration, or any biomarkers, to define "athletic gender" [3]. Resolving these issues will require the scientific and sports medicine community to employ innovative research ideas [e.g., a combination of cell, animal, and human research paradigms (Table 1)] to generate the biological data needed to inform the inclusion or exclusion of transwomen and DSD women athletes in elite female sports.

Areas of research focus could include better methods for quantifying bioavailable testosterone, also known as free testosterone, as a potentially better alternative to total circulating testosterone as a criterion for participation in the female category of sports. Bioavailable testosterone is the testosterone that is taken up and used by the body's cells and could be measured in conjunction with an allowance for androgen insensitivity [3]. An increase in bioavailable testosterone over time seems to induce a greater increase in muscle mass and strength [60], although this finding has been recently disputed [61]. In contrast, when bioavailable testosterone was reduced to castrate levels in young men, isometric strength did not increase after resistance exercise training [62]. Assuming these findings are replicated and if extrapolated to elite DSD women athletes and transwomen athletes, they would imply that decreasing bioavailable testosterone concentrations would mitigate to some extent any previous sporting advantage due to the previously high testosterone concentrations. This is a particularly encouraging future avenue of research.

The role of testosterone in muscle anabolism (i.e., tissue growth, substrate restoration, and recovery) and catabolism (i.e., tissue breakdown and metabolic regulation) is well described [63] and, therefore, could be another avenue of research. The hypothesis is that the low testosterone concentrations induced in transwomen or DSD women will impact negatively on muscle performance and recovery. Therefore, it is essential that researchers replicate or determine the precise time frame, individual variability, and mechanism(s) of this drop off in strength with HRT in trained athletes.

\subsection{Genetics}

Another pertinent issue is genetic factors (i.e., sex chromosome composition) in influencing athletic performance. Boys and girls demonstrate differences in a range of physical characteristics, including body composition and skinfold thickness [64], height, and explosive strength, even before puberty [65], suggesting that sex chromosome composition plays a role in determining differences in adult athletic performance. Consistent with this, different populations of muscle cells may express different phenotypes of androgen sensitivity, raising the possibility that the muscle response to training may be different between men and women at the same testosterone concentrations. Animal model studies are a feasible option to examine the influences of sex chromosomes and pubertal hormones. For example, the four core genotypes mouse model which incorporates mice with four different combinations of gonads and sex chromosomes [66, 67], has helped identify the influence of sex chromosomes on physical traits, such as obesity and food intake $[68,69]$. This model represents an ideal opportunity to study muscle function in the present context as the different combinations of gonads and sex chromosomes will result in different testosterone concentrations. This model may highlight the true effect of testosterone on muscle function. 


\subsection{Androgen Receptor Function}

Elucidating further androgen receptor function is another relevant future avenue of research. Androgen receptors can be modulated by specific proteins called coregulators [70-72] or mediated via the activation of membrane-bound protein receptors to initiate intracellular signalling pathways [73], which can occur even in the presence of low levels of androgens [74]. Investigations into the non-genomic actions of the androgen receptor have been limited to in vitro studies $[75,76]$ rather than in vivo due to the lack of an appropriate animal model that can distinguish between genomic and non-genomic receptor actions [75]. Androgen receptor knockout mice such as DBD-ARKO [40], which has a deletion of the second zinc finger of the DNA-binding domain, has been created for such research purposes. Given the inherent challenges of human studies, investigators need to adopt similar creative approaches if they are to elucidate the role of androgen receptors in elite DSD women and transwomen athletes.

\subsection{Athlete Health}

It is important to note that the World Medical Association has urged physicians not to implement the World Athletics policy on classifying women athletes, arguing that the policy is not in line with medical ethics and could be harmful to the athlete [77]. This argument is an outdated approach to protect the privacy of patients. If the athlete is fully informed of the consequences of treatment and not coerced into undergoing treatment, the athlete has free choice to do so (Table 1), which is a fundamental human right [32]. However, when the sex of an athlete is challenged or uncertain, eligibility would need to be determined for women's events. Such a concept to request eligibility is currently being implemented by World Rowing [56]. The justification is that it is ethical and may be necessary for a medical doctor to assist an athlete in determining their eligibility for a sex-restricted event. This requirement is not about treatment and treatment choices, which are always private and not relevant to the sports community. This process is essential to ensure all athletes, including transwomen and DSD women athletes, can compete on an even playing field with cisgender athletes, and currently, as the best proxy, transgender athletes have to demonstrate testosterone concentrations in a similar range to those athletes they wish to compete against. The eligibility of DSD women athletes must not only follow the same principles based on testosterone concentrations, but also needs to consider testosterone receptor function.

The health of athletes should be the number one priority of any sport, and it is clear that World Rugby's new transwomen exclusion policy [58] has the health of athletes at the heart of its policy. However, such exclusion policies should be based on generally accepted scientific consensus, including results from studies conducted in transwomen athletes. The authors of the World Rugby guidelines may be correct in their assumptions using hypothetical modelling of elite male versus elite female athletes [58]; however, until relevant transwomen athletic performance data become available, there is just as much circumstantial evidence to support this policy by World Rugby as there is to oppose it. For example, a study of young untrained women with polycystic ovary syndrome found greater muscle mass did not equate to greater peak muscle force [78]. There is an urgent need, therefore, for well-designed longitudinal studies throughout a transwomen's transition that assesses at regular intervals the main indices of performance relevant to all sports. Such data will prove invaluable to directly evaluate the true safety risks inherent in transwomen playing in the elite female category of sport.

\subsection{Muscle Memory}

Muscle memory refers to the persistence of cellular phenotype related to previous testosterone exposure [79]. Research shows that in addition to hormone concentrations, the number of myonuclei can affect skeletal muscle training $[79,80]$. Indeed, muscle cells have multiple nuclei and their number increases with muscle hypertrophy [81, 82]. In female mice, short-term treatment with testosterone increased both muscle fibre cross-sectional area (CSA) and myonuclei number [79]. After cessation of exposure, muscle fibre CSA reverted to that of the control arm, but the number of myonuclei remained $42 \%$ higher than controls for at least 3 months. These resident myonuclei facilitated enhanced muscle hypertrophy during 6-day resistance training overload (31\% increase in the fibre CSA vs. $6 \%$ in controls); this increase remained 20\% higher compared with controls after 14-day overload [79]. The number of myonuclei not only reflects the current size of the fibre, but also the history of the fibre. Current data might fit a "peak pegging" hypothesis, where the number of myonuclei found in the fibre represents the largest size the fibre has achieved, and new myonuclei are only added if the fibre grows beyond that size. However, this "peak pegging" hypothesis found in female mice does not transfer to young healthy, physically active women. Horwath et al. showed no change in the myonuclei content following a 10-week testosterone administration of $10 \mathrm{mg}$ daily protocol [83] coupled with an interesting finding of a $31 \%$ increase in satellite cells associated with type II fibres in the testosterone group. Satellite cells exit quiescence by extrinsic mechanical stretch to the fibre, generating differentiated cells and self-renewing stem cells by asymmetric division 
[84], meaning that the myofibres could feasibly repair more quickly with exogenous testosterone administration.

Testosterone has been shown to increase the myonuclear number in men in a dose-dependent manner alongside muscle fibre CSA being well correlated with the myonuclear number [81, 82]. Nevertheless, further data are needed to confirm the extent to which myonuclei are retained over time after human muscle fibres have been exposed to a high testosterone environment. If high numbers of myonuclei are confirmed to be retained in transwomen or DSD women athletes, these results could imply that an advantage of previously high testosterone concentrations remains even after testosterone suppression. The relevant question would remain whether this potential effect is relevant to regulations that seek to prohibit individuals who have this potential advantage from competition.

\subsection{Previous Failings Present Opportunity}

Finally, it is important to stress that the current physiological data are insufficient to adequately inform policy and result from both a distinct lack of research funding and a limited number of elite athletes available to participate in this research area. For eligibility to be determined in the fairest manner possible, more funding and subsequent research are required to allow specialists in biological sciences and sports medicine to conduct experiments to determine the best solutions for integrating DSD women and transwomen athletes into the elite level of female sport.

\subsection{FIMS Consensus Statements for the Integration of DSD Women and Transwomen Athletes into Elite Female Sport}

Although serum testosterone concentrations constitute an indicator of androgen production and availability, a reliable biological index of androgen action is still lacking. Promising new developments in sport and exercise science are destined to contribute to the fair inclusion of DSD women and transwomen athletes. A well-coordinated multidisciplinary international research approach should include welldesigned, controlled studies on the effect of testosterone on training and sports performance. Providing scientific evidence to use a system of biology multi-omics adequately and ethically (i.e., genomics, transcriptomics, metabolomics, and proteomics) to generate the necessary data and downstream biomarkers will be needed to address all open issues. There must be a transparent roadmap for the scientific community to focus on the best possible outcome of such new research. The authors, therefore, propose the following FIMS consensus statements and roadmap to facilitate the integration of DSD women and transwomen athletes into elite female sport:
- The inclusion of a third category in elite sport is not currently plausible, as the numbers of elite DSD women and transwomen athletes are relatively small.

- The prevalence of transwomen athletes in elite competition is likely to increase in the future, due to the increased visibility of transgender individuals in society $[85,86]$, which in turn may drive more people to consider expressing their chosen gender identity [87]. Research into transwomen sporting performance is highly relevant for leading scientists, leading clinicians, sport's governing bodies, and the World Anti-Doping Agency and is already a priority for the IOC [88].

- Transwomen have the right to compete in sports. However, cisgender women have the right to compete in a protected category.

- Any inclusion or exclusion policies on DSD women and/ or transwomen athletes should be free of any social and/ or religious prejudice, bias, or discrimination and should be based solely on the governance of fair competition.

- As each sport can vary greatly in terms of physiological demands, we support the view held also by others [43] stating that individual sport's governing bodies should develop their own individual policies based on broader guidelines developed on the best available scientific evidence, determined experimentally from a variety of sources with a particular preference for studies on transwomen and DSD women athletes.

- With data showing reductions in haemoglobin following testosterone suppression [45], obtaining data on DSD women and transwomen athletes' cardiovascular performance, such as maximal oxygen uptake, should be a priority for researchers due to the importance of the cardiovascular system in numerous sports performance contexts.

- The use of serum testosterone concentrations as the primary biomarker to regulate the inclusion of athletes into male and female categories is currently the most justified solution as it is supported by the available scientific literature (Table 1) and should be implemented at the elite level, where there is an emphasis on performance enhancement.

- DSD women or transwomen athletes should be fully informed by medical personnel of the risks and consequences of testosterone suppression treatment and must never be coerced or forced into testosterone suppression. The athletes must be free to make the decision that is best for them (Table 1).

- No sport's governing body should provide recommendations on treatment; this should be done by medical personnel (Table 1).

- If DSD women and transwomen athletes choose not to have suppressed testosterone, as is their right, they cannot compete in the restricted female category with high 
testosterone concentrations above the policy threshold. Instead, they should be offered the chance to compete in the male category.

- A testosterone concentration threshold of $5 \mathrm{nmol} / \mathrm{L}$ in DSD women and transwomen athletes should be used as a global recommendation for sport's governing bodies at this present time and may be modified as new evidence arises for an event or sport-specific concentrations (Table 1).

- The statement on the testosterone concentration threshold for transwomen and DSD women athletes was the only point of contention for the FIMS Panel. All 70 authors voted, of whom $87 \%$ were in favour of the $5 \mathrm{nmol} / \mathrm{L}$ threshold, $2 \%$ of authors were in favour of a threshold of $8 \mathrm{nmol} / \mathrm{L}, 2 \%$ were in favour of a threshold around the upper testosterone concentration of normal healthy females of $0.2-1.7 \mathrm{nmol} / \mathrm{L}$ [89], and $8 \%$ of authors were in favour of no change to the limit until further evidence was acquired. This large but not unanimous majority consensus highlights the area most in need of research, i.e., altered bioavailability of testosterone and performance indices in DSD women and transwomen athletes.

- New innovative avenues must be explored to guide improved, up to date policy (Table 1), for example, quantifying bioactive testosterone and individual sensitivity to testosterone, the role of sex chromosomes in athletic performance, the role of androgen receptors, and the extent to which muscle memory is retained after high testosterone exposure. In addition, identification of other biomarkers (e.g., metabolomics, proteomics) that may better differentiate individual sensitivity to testosterone is needed. Liquid chromatography-mass spectrometry is well accepted as the preferred technique for the analysis of testosterone [90, 91].

- The best available scientific methods, such as welldesigned, controlled studies, must be utilised to acquire new scientific evidence on sporting performance measures to derive policies on DSD women and/or transwomen sporting participation. This should be on a sportby-sport basis when the evidence arises, rather than the universal approach to sports regulations at present due to the lack of individual sports data.

\subsection{Dissenting Opinions During Consensus Discussions}

During the consensus discussions, there was a constructive debate on the testosterone limit in the elite category of female sports. One author agreed that the concentration of $5 \mathrm{nmol} / \mathrm{L}$ was a median value between the upper and lower ranges of female and male testosterone. However, the $5 \mathrm{nmol} / \mathrm{L}$ level adopted by World Athletics is based on the inference that there is a relationship between performance and testosterone concentrations and is meant to represent the value above which a performance advantage is no longer within the bounds of healthy cisgender females. This assumption is likely false due to the multifactorial nature of different sports. Although there is evidence to suggest that performance of female athletes with high testosterone levels may be enhanced, it is still a contentious issue that requires research before and after testosterone suppression to identify where the testosterone threshold should be set for such athletes, and the limit may have to follow a sport-by-sport evidenced basis instead of a holistic approach.

The authors also discussed the issue of athletes' health, which is timely given the announcement of World Rugby's transgender guideline which excludes transwomen players to safeguard cisgender female players at the international level. One author opposed the "one size does not fit all" notion of World Rugby's policy due to its assumption that all transwomen are larger in stature and heavier than their cisgender counterparts. This assumption is due to studies like Roberts et al. showing that transwomen are heavier when presented as a pre-treatment average [53]. However, some cisgender women athletes are taller than transwomen or have greater muscle mass than transwomen and anthropometric variation is a part of sport. If the modelling scenario in World Rugby's policy of a "typical male tackler mass" involved in a rugby tackle with a "typical female tackler mass" [58] is confirmed, an exclusion policy could be implemented on an individual basis and resolving all the practical challenges that this would entail. Safety in sport is of great importance and exclusion based on safety is a justifiable cause but exclusion needs to be evidenced-based and include some consideration of transwomen athletic performance metrics.

Another author strongly affirmed that all cut-offs for hormones that are out of normal ranges for age and/or gender are pathological, not physiological, and are associated with different side effects, some of them increasing health risks and some potentially useful at different levels for physiological performance. The author stated, "that as sports physicians we have to decide if firstly, we protect athlete's health issues or social issues" and that sport physicians should mimic society's physicians and be "a cornerstone for athletes health".

\section{Conclusions}

Ultimately, even the most evidence-based policies will not eliminate differences in sporting performance between athletes in the elite category of female sports. However, any advantage held by a person belonging to an athlete in this category could be considered part of the athlete's unique individuality. Whatever the solution, there is an urgent need for a well-coordinated multidisciplinary international 
research program, backed by appropriate research grant funding and athlete participation, to generate the evidence to inform future objective policy decisions. Such decisions should be based on the best available scientific evidence from the best available scientific practice and the decisions made will also require a firm political resolve to fairly integrate transwomen and DSD women athletes into elite female sport.

\section{Declarations}

Funding This manuscript was not funded.

Conflict of interest/competing interst Blair Hamilton, Gicard Lima, James Barrett, Leighton Seal, Alexander Kolliari-Turner, Guan Wang, Antonia Karanikolou, Xavier Bigard, Herbert Lollgen, Petra Zupet, Anca Ionescu, Andre Debruyne, Nigel Jones, Karin Vonbank, Federica Fagnani, Chiara Fossati, Maurizio Casasco, Demitri Constantinou, Bernd Wolfarth, David Niederseer, Andrew Bosch, Borja Muniz, Jose Casajus, Christian Schneider, Sigmund Loland, Michele Verroken, Pedro Manonelles Marqueta, Francisco Arroyo, André Pedrinelli, Kostas Natsis, Evert Verhagen, William Roberts, José Kawazoe Lazzoli, Rogerio Friedman, Ali Erdoğan, Ana Cintron, Patrick Yung, Christa Janse van Rensburg, Dimakatso Ramagole, Sandra Rozenstoka, Felix Drummond, Theodora Papadopoulou, Paulette Kumi, Richard TwycrossLewis, Joanna Harper, Vasileios Skiadas, Jonathan Shurlock, Kumpei Tanisawa, Jane Seto, Kathryn North, Siddhartha Angadi, Maria Patino, Mats Borjesson, Luigi Di Luigi, Michiko Dohi, Jeroen Swart, James Bilzon, Victoriya Badtieva, Irina Zelenkova, Juergen Steinacker, Norbert Bachl, Fabio Pigozzi, Michael Geistlinger, Dimitrios Goulis, Fergus Guppy, Nick Webborn, Bulent Yildiz, Mike Miller, Patrick Singleton and Yannis Pitsiladis declare that they have no conflicts of interest relevant to the content of this review.

Ethics approval Not applicable

Consent to participate Not applicable

Consent for publication Not applicable

\section{Availability of data and material Not applicable}

Code availability Not applicable

Author Contributions Yannis Pitsiladis was responsible for the manuscript conception. The first draft of the manuscript was written by $\mathrm{BH}$ and YP and all authors commented on subsequent versions of the manuscript. All authors read and approved the final manuscript.

\section{References}

1. Archives TN. Equality Act 2010. http://www.legislation.gov.uk/ ukpga/2010/15/section/195. Accessed 4 Mar 2020.

2. Sánchez FJ, Martínez-Patiño MJ, Vilain E. The new policy on hyperandrogenism in elite female athletes is not about "sex testing." J Sex Res. 2013;50(2):112-5.

3. Harper J, Martinez-Patino M-J, Pigozzi F, Pitsiladis Y. Implications of a third gender for elite sports. Curr Sports Med Rep. 2018;17(2):42-4.
4. Harper J, Lima G, Kolliari-Turner A, Malinsky FR, Wang G, Martinez-Patino MJ, et al. The fluidity of gender and implications for the biology of inclusion for transgender and intersex athletes. Curr Sports Med Rep. 2018;17(12):467-72. https://doi.org/10.1249/ JSR.0000000000000543.

5. Sudai $\mathrm{M}$. The testosterone rule-constructing fairness in professional sport. J Law Biosci. 2017;4(1):181-93.

6. Jones BA, Arcelus J, Bouman WP, Haycraft E. Sport and transgender people: a systematic review of the literature relating to sport participation and competitive sport policies. Sports Med. 2017;47(4):701-16.

7. Committee IO. Olympic Charter. 2020. www.olympic.org/docum ents/olympic-charter. Accessed 15 Jun 2020.

8. Walker PL, Cook DC. Brief communication: gender and sex: vive la difference. Am J Phys Anthropol. 1998;106(2):255-9.

9. Vilain E, Betancurt JO, Bueno-Guerra N, Martinez-Patiño MJ. Transgender athletes in elite sport competitions. Transgender Athletes in Competitive Sport. Oxfordshire: Routledge; 2017.

10. Reisner SL, Hughto JM. Comparing the health of non-binary and binary transgender adults in a statewide non-probability sample. PLoS ONE. 2019;14(8):e0221583.

11. NHS. Differences in sex development. 2019. https://www.nhs. uk/conditions/differences-in-sex-development/. Accessed 15 Sep 2020.

12. Jung EJ, Im DH, Park YH, Byun JM, Kim YN, Jeong DH, et al. Female with 46. XY karyotype Obstet Gynecol Sci. 2017;60(4):378-82.

13. Court GFC. Act on amending the act on the civil status of persons (Personenstandsgesetz). In: Article 4 of the Act of 18.12.2018. 2018. http://www.gesetze-im-internet.de/englisch_gg/englisch_ gg.pdf. BGBl. 2018 IS. 2369.

14. Court TFC. Order of the First Senate of 10th October. 2017. http:// www.bverfg.de/e/rs20171010_1bvr201916en.html. Accessed 25 Jun 2020.

15. Sport CoAf. CAS 2014/A/3759 Dutee Chand v. Athletics Federation of India (AFI) \& The International Association of Athletics Federations (IAAF). 2014. https://www.doping.nl/media/kb/3317/ CAS\%202014_A_3759\%20Dutee\%20Chand\%20vs.\%20AFI\% 20\%26\%20IAAF\%20\%28S\%29.pdf. Accessed 26 Feb 2020.

16. Sport CoAf. CAS 2018/0/5794 Mokgadi Caster Semenya v. International Association of Athletics Federations and CAS 2018/0/5798 Athletics South Africa v. International Association of Athletics Federations. 2018. https://www.tas-cas.org/fileadmin/ user_upload/CAS_Award_-_redacted_-_Semenya_ASA_IAAF. pdf. Accessed 26 Feb 2020.

17. Council UNHR. Promotion of the cultural rights of everyone and respect for cultural diversity. 2019. https://documents-dds-ny.un. org/doc/UNDOC/GEN/G19/098/67/PDF/G1909867.pdf?OpenE lement. Accessed 19 April 2020.

18. Ellaithi M, Kamel A, Saber O, Hiort O. Consanguinity and disorders of sexual developments in the Sudan. Sudan JMS. 2011;6(4):267-70.

19. Handelsman DJ, Hirschberg AL, Bermon S. Circulating testosterone as the hormonal basis of sex differences in athletic performance. Endocr Rev. 2018;39(5):803-29. https://doi.org/10.1210/ er.2018-00020.

20. Bermon S, Garnier PY, Hirschberg AL, Robinson N, Giraud S, Nicoli R, et al. Serum androgen levels in elite female athletes. J Clin Endocrinol Metab. 2014;99(11):4328-35.

21. Morel Y, Rey R, Teinturier C, Nicolino M, Michel-Calemard L, Mowszowicz I, et al. Aetiological diagnosis of male sex ambiguity: a collaborative study. Eur J Pediatr. 2002;161(1):49-59.

22. Hirschberg AL, Knutsson JE, Helge T, Godhe M, Ekblom M, Bermon S, et al. Effects of moderately increased testosterone concentration on physical performance in young women: a double 
blind, randomised, placebo controlled study. Br J Sports Med. 2019;54:599-604.

23. Bermon S. Androgens and athletic performance of elite female athletes. Curr Opin Endocrinol Diabetes Obes. 2017;24(3):246-51.

24. Bermon S, Garnier P-Y. Serum androgen levels and their relation to performance in track and field: mass spectrometry results from 2127 observations in male and female elite athletes. Br J Sports Med. 2017;51(17):1309-14.

25. Federations. IAoA. Eligibility Regulations for the Female Classification (Athletes with Differences of Sex Development). Version 1.0. 2018. www.iaaf.org/about-iaaf/documents/rules-regulations. Accessed 6 March 2020.

26. Pielke R, Tucker R, Boye E. Scientific integrity and the IAAF testosterone regulations. Int Sports Law J. 2019;19(1-2):18-26.

27. Menier A. Use of event-specific tertiles to analyse the relationship between serum androgens and athletic performance in women. $\mathrm{Br}$ J Sports Med. 2018;52(23):1540.

28. Koh B, Adair D, Elphick L. Not by gender, not by sex, but by testosterone saith the IAAF: International Athletics and the new female eligibility regulations. Law Sport J. Available at SSRN: https://ssrn.com/abstract=31846642018.

29. Bermon S, Hirschberg AL, Kowalski J, Eklund E. Serum androgen levels are positively correlated with athletic performance and competition results in elite female athletes. Br J Sports Med. 2018;52(23):1531-2.

30. Loland S. Caster Semenya, athlete classification, and fair equality of opportunity in sport. J Med Ethics. 2020;46(9):584-90.

31. Federations. IAoA. Eligibility Regulations for the female classification (athletes with differences of sex development). Version 2.0. 2019. www.iaaf.org/about-iaaf/documents/rules-regulations. Accessed 1 Jun 2020

32. Hamilton BR, Martinez-Patiño MJ, Barrett J, Seal L, Tucker R, Papadopoulou T, et al. Response to the United Nations Human Rights Council's report on race and gender discrimination in sport: an expression of concern and a call to prioritise research. Sports Med. 2020. https://doi.org/10.1007/s40279-020-01380-y.

33. Court SFS. DSD Regulations: Caster Semenya's appeal against the decision of the Court of Arbitration for Sport dismissed. 2020. https://www.bger.ch/files/live/sites/bger/files/pdf/en/4A_248 2019_yyyy_mm_dd_T_e_18_18_10.pdf. Accessed 10 Oct 2020.

34. Johnson J, Sotherton K. Caster Semenya ruling: The case for and against IAAF's testosterone regulations. The Telegraph, Online. 2019. https://www.telegraph.co.uk/athletics/2019/05/02/castersemenya-ruling-case-against-iaafs-testosterone-regulations/. Accessed 8 Apr 2020.

35. Tannenbaum C, Bekker S. Sex, gender, and sports. BMJ. 2019;364:11120.

36. Committee TGAFR. Fiscal Note HB 1572-2077. 2020. http:// www.capitol.tn.gov/Bills/111/Fiscal/HB1572.pdf. Accessed 1 Apr 2020.

37. Luevano A. Fairness In Women's Sports Act bans some transgender athletes. Local News 8 and KIDK Eyewitness News 3, Online 2020. https://localnews8.com/sports/2020/04/02/fairness-in-womens-sports-act-bans-some-transgender-athletes/. Accessed 15 Jun 2020.

38. Idaho TSo. Fairness in Women's Sports Act. 2020. https://legis lature.idaho.gov/sessioninfo/billbookmark/?yr $=2020 \& \mathrm{bn}=$ H0500. Accessed 17 Apr 2020.

39. Freedom AD. Idaho governor signs Fairness for Women in Sports Act into law. 2020. http://www.adfmedia.org/News/PRDetail/ 10948. Accessed 17 Apr 2020.

40. Press A. Civil rights groups file suit against Idaho ban on trans athletes in women's sports. The Guardian. 2020. https://www. theguardian.com/sport/2020/apr/15/idaho-transgender-ban-womens-sports-lawsuit. Accessed 17 Apr 2020.
41. Minsberg T. 'Boys are boys and girls are girls': Idaho Is first state to bar some transgender athletes. The New York Times, Online. 2020. https://www.nytimes.com/2020/04/01/sports/transgenderidaho-ban-sports.html. Accessed 17 Apr 2020.

42. Cavanagh SL, Sykes H. Transsexual bodies at the Olympics: the international Olympic Committee's policy on transsexual athletes at the 2004 Athens Summer Games. Body Soc. 2006;12(3):75-102.

43. Hilton EN, Lundberg TR. Transgender women in the female category of sport: perspectives on testosterone suppression and performance advantage. Sports Med. 2020. https://doi.org/10.1007/ s40279-020-01389-3.

44. Pitsiladis Y, Harper J, Betancurt JO, Martinez-Patino M-J, Parisi A, Wang G, et al. Beyond fairness: the biology of inclusion for transgender and intersex athletes. Curr Sports Med Rep. 2016;15(6):386-8.

45. Gooren LJ, Bunck MC. Transsexuals and competitive sports. Eur J Endocrinol. 2004;151(4):425-30.

46. Gooren LJ, Giltay EJ, Bunck MC. Long-term treatment of transsexuals with cross-sex hormones: extensive personal experience. J Clin Endocrinol Metab. 2008;93(1):19-25.

47. Karalexi MA, Georgakis MK, Dimitriou NG, Vichos T, Katsimpris A, Petridou ET, et al. Gender-affirming hormone treatment and cognitive function in transgender young adults: a systematic review and meta-analysis. Psychoneuroendocrinology. 2020;119:104721.

48. T'Sjoen G, Weyers S, Taes Y, Lapauw B, Toye K, Goemaere S, et al. Prevalence of low bone mass in relation to estrogen treatment and body composition in male-to-female transsexual persons. J Clin Densitom. 2009;12(3):306-13.

49. Harper J. Race times for transgender athletes. J Sport Cult Ident. 2015;6(1):1-9.

50. Grubb H. Models for comparing athletic performances. J R Stat Soc Ser D Stat. 1998;47(3):509-21.

51. Wiik A, Lundberg T, Rullman E, Andersson D, Holmberg M, Mandić M, et al. Muscle strength, size, and composition following 12 months of gender-affirming treatment in transgender individuals. J Clin Endocrinol. 2020;105(3):e805-13.

52. NHS. Gender dysphoria. The National Health Service. 2020. https://www.nhs.uk/conditions/gender-dysphoria/. Accessed 29 Jul 2020

53. Roberts TA, Smalley J, Ahrendt D. Effect of gender affirming hormones on athletic performance in transwomen and transmen: implications for sporting organisations and legislators. Br J Sports Med. 2020. https://doi.org/10.1136/bjsports-2020-102329.

54. Commitee IO. Consensus Meeting on Sex Reassignment and Hyperandrogenism. 2015. https://stillmed.olympic.org/Docum ents/Commissions_PDFfiles/Medical_commission/2015-11_ ioc_consensus_meeting_on_sex_reassignment_and_hyperandro genism-en.pdf. Accessed 20 Feb 2020.

55. Athletics W. Eligibility Regulations Transgender Athletes. 2019. https://www.worldathletics.org/about-iaaf/documents/book-ofrules. Accessed 22 Oct 2020.

56. Rowing W. Rule 13 and Bye law to rule 13- Men's and Women's Events. 2020. www.worldrowing.com. Accessed 2 Dec 2020.

57. Internationale UC. Rule 13.5.028. 2020. https://www.uci.org/docs/ default-source/rules-and-regulations/part-xiii---medical-rules--01.03.2020.pdf. Accessed 5 Dec 2020.

58. Rugby W. World Rugby Transgender Guideline. Online. 2020. https://playerwelfare.worldrugby.org/?documentid=231. Accessed 2 Nov 2020.

59. Ingle $\mathrm{S}$. RFU clears trans women to keep playing domestic women's rugby in England. The Guardian. 2020. https://www.thegu ardian.com/sport/2020/oct/14/rfu-clears-trans-women-to-playwomens-rugby-at-all-levels-in-england?fbclid=IwAR359QKh 
JiCxKr8a_u8yX1vGNN7opyvA52uJVykCfTR7B9ehb2EJvc8_ kOM. Accessed 2 Nov 2020.

60. Rønnestad BR, Nygaard H, Raastad T. Physiological elevation of endogenous hormones results in superior strength training adaptation. Eur J Appl Physiol. 2011;111(9):2249-59.

61. Schwanbeck SR, Cornish SM, Barss T, Chilibeck PD. Effects of training with free weights versus machines on muscle mass, strength, free testosterone, and free cortisol levels. J Strength Cond Res. 2020;34(7):1851-9.

62. Kvorning T, Andersen M, Brixen K, Madsen K. Suppression of endogenous testosterone production attenuates the response to strength training: a randomized, placebo-controlled, and blinded intervention study. Am J Physiol Endocrinol Metab. 2006;291(6):E1325-32.

63. Kraemer WJ, Ratamess NA, Nindl BC. Recovery responses of testosterone, growth hormone, and IGF-1 after resistance exercise. J Appl Physiol. 2017;122(3):549-58.

64. Kelso A, Vogel K, Steinacker JM. Ultrasound measurements of subcutaneous adipose tissue thickness show sexual dimorphism in children of three to five years of age. Acta Paediatr. 2019;108(3):514-21.

65. Marta CC, Marinho DA, Barbosa TM, Izquierdo M, Marques MC. Physical fitness differences between prepubescent boys and girls. J Strength Cond Res. 2012;26(7):1756-66.

66. Arnold AP, Chen X. What does the "four core genotypes" mouse model tell us about sex differences in the brain and other tissues? Front Neuroendocrinol. 2009;30(1):1-9.

67. Burgoyne PS, Arnold AP. A primer on the use of mouse models for identifying direct sex chromosome effects that cause sex differences in non-gonadal tissues. Biol Sex Differ. 2016;7(1):68.

68. Chen X, McClusky R, Chen J, Beaven SW, Tontonoz P, Arnold AP, et al. The number of $x$ chromosomes causes sex differences in adiposity in mice. PLoS Genet. 2012;8(5):e1002709.

69. Chen X, Wang L, Loh DH, Colwell CS, Taché Y, Reue K, et al. Sex differences in diurnal rhythms of food intake in mice caused by gonadal hormones and complement of sex chromosomes. Horm Behav. 2015;75:55-63.

70. Heinlein CA, Chang C. Androgen receptor (AR) coregulators: an overview. Endocr Rev. 2002;23(2):175-200.

71. Heemers HV, Tindall DJ. Androgen receptor (AR) coregulators: a diversity of functions converging on and regulating the AR transcriptional complex. Endocr Rev. 2007;28(7):778-808.

72. van de Wijngaart DJ, Dubbink HJ, van Royen ME, Trapman J, Jenster G. Androgen receptor coregulators: recruitment via the coactivator binding groove. Mol Cell Endocrinol. 2012;352(1-2):57-69.

73. Papakonstanti EA, Kampa M, Castanas E, Stournaras C. A rapid, nongenomic, signaling pathway regulates the actin reorganization induced by activation of membrane testosterone receptors. J Mol Endocrinol. 2003;17(5):870-81.

74. Lamont KR, Tindall DJ. Minireview: Alternative activation pathways for the androgen receptor in prostate cancer. Mol Endocrinol. 2011;25(6):897-907.

75. Davey RA, Grossmann M. Androgen receptor structure, function and biology: from bench to bedside. Clin Biochem Rev. 2016;37(1):3.

76. Heinlein CA, Chang C. The roles of androgen receptors and androgen-binding proteins in nongenomic androgen actions. $\mathrm{J}$ Mol Endocrinol. 2002;16(10):2181-7.
77. Association WM. World Medical Association urges physicians not to implement IAAF rules on classifying women athletes. 2020. https://www.wma.net/news-post/wma-urges-physicians-not-toimplement-iaaf-rules-on-classifying-women-athletes/. Accessed 8 Jul 2020.

78. Caliskan Guzelce E, Eyupoglu N, Torgutalp S, Aktoz F, Portakal $\mathrm{O}$, Demirel $\mathrm{H}$, et al. Is muscle mechanical function altered In polycystic ovary syndrome? J Endocr Soc. 2019;3(Supplement_1):MON-205.

79. Egner IM, Bruusgaard JC, Eftest $\varnothing 1$ E, Gundersen K. A cellular memory mechanism aids overload hypertrophy in muscle long after an episodic exposure to anabolic steroids. J Physiol. 2013;591(24):6221-30.

80. Bruusgaard JC, Johansen I, Egner I, Rana Z, Gundersen K. Myonuclei acquired by overload exercise precede hypertrophy and are not lost on detraining. Proc Natl Acad Sci USA. 2010;107(34):15111-6.

81. Sinha-Hikim I, Roth SM, Lee MI, Bhasin S. Testosterone-induced muscle hypertrophy is associated with an increase in satellite cell number in healthy, young men. Am J Physiol Endocrinol Metab. 2003;285(1):E197-205.

82. Sinha-Hikim I, Cornford M, Gaytan H, Lee ML, Bhasin S. Effects of testosterone supplementation on skeletal muscle fiber hypertrophy and satellite cells in community-dwelling older men. J Clin Endocrinol Metab. 2006;91(8):3024-33.

83. Horwath O, Apró W, Moberg M, Godhe M, Helge T, Ekblom M, et al. Fiber type-specific hypertrophy and increased capillarization in skeletal muscle following testosterone administration in young women. J Appl Physiol. 2020;128(5):1240-50.

84. Le Grand F, Rudnicki MA. Skeletal muscle satellite cells and adult myogenesis. Curr Opin Cell Biol. 2007;19(6):628-33.

85. Aitken M, Steensma TD, Blanchard R, VanderLaan DP, Wood H, Fuentes A, et al. Evidence for an altered sex ratio in clinic-referred adolescents with gender dysphoria. J Sex Med. 2015;12(3):756-63.

86. De Vries A, Kreukels B, T'sjoen G, Ålgars M, Mattila A. Increase of referrals to gender identity clinics: a European trend. Transgender Healthc Europe. Book of abstracts. 2015.

87. Bouman WP, de Vries AL, T'Sjoen G. Gender dysphoria and gender incongruence: an evolving inter-disciplinary field. Milton Park: Taylor \& Francis; 2016.

88. Committee. IO. Call for Applications. 2019. https://www.olymp ic.org/news/2019-call-for-applications. Accessed 16 Apr 2020.

89. NHS. Testosterone. 2020. https://www.nbt.nhs.uk/severn-patho logy/requesting/test-information/testosterone. Accessed 2 Aug 2020.

90. Stanczyk FZ, Clarke NJ. Advantages and challenges of mass spectrometry assays for steroid hormones. J Steroid Biochem Mol Bio. 2010;121(3-5):491-5.

91. Martínez-Escribano A, Maroto-García J, Ruiz-Galdón M, BarriosRodríguez R, Álvarez-Millán JJ, Cabezas-Sánchez P, et al. Measurement of serum testosterone in nondiabetic young obese men: comparison of direct immunoassay to liquid chromatographytandem mass spectrometry. Biomolecules. 2020;10(12):1697. 


\section{Authors and Affiliations}

Blair R. Hamilton ${ }^{2,3}(1) \cdot$ Giscard Lima $^{1,4}\left(\mathbb{0} \cdot\right.$ James Barrett $^{3} \cdot$ Leighton Seal $^{3} \cdot$ Alexander Kolliari-Turner $^{2}(\mathbb{0} \cdot$ Guan Wang $^{65} \cdot$ Antonia Karanikolou $^{2} \cdot$ Xavier Bigard $^{5,6,7} \cdot$ Herbert Löllgen $^{6} \cdot$ Petra Zupet $^{6} \cdot$ Anca lonescu $^{6}$. Andre Debruyne $^{6,7} \cdot$ Nigel Jones $^{8,9} \cdot$ Karin Vonbank $^{10} \cdot$ Federica Fagnani $^{4} \cdot$ Chiara Fossati $^{4,11}$ (1) . Maurizio Casasco $^{6,7,12}$. Demitri Constantinou ${ }^{7,13} \cdot$ Bernd Wolfarth $^{7,14} \cdot$ David Niederseer $^{15}$ (1) . Andrew Bosch ${ }^{16}$. Borja Muniz-Pardos ${ }^{17}$ (1) . José Antonio Casajus ${ }^{17}$ (i) . Christian Schneider ${ }^{7,18}$. Sigmund Loland ${ }^{19}$ (1) - Michele Verroken ${ }^{20,21}$ (1) Pedro Manonelles Marqueta ${ }^{7,22}$. Francisco Arroyo ${ }^{7,23}$ (1) André Pedrinelli $^{7,24} \cdot$ Konstantinos Natsis $^{6,7,25,26}$ - Evert Verhagen ${ }^{27}$. William O. Roberts ${ }^{7,28}$ (1) José Kawazoe Lazzoli ${ }^{7,29} \cdot$ Rogerio Friedman $^{30}$ - Ali Erdogan ${ }^{7,31}$. Ana V. Cintron ${ }^{7,32}$. Shu-Hang Patrick Yung ${ }^{7,33}$. Dina C. Janse van Rensburg ${ }^{34}$. Dimakatso A. Ramagole ${ }^{34}$. Sandra Rozenstoka ${ }^{6,7,35}$. Felix Drummond ${ }^{6,7,36}$. Theodora Papadopoulou ${ }^{6,7,37}$. Paulette Y. O. Kumi ${ }^{38}$. Richard Twycross-Lewis ${ }^{39}$ (D) Joanna Harper ${ }^{40}$. Vasileios Skiadas ${ }^{41}$. Jonathan Shurlock ${ }^{42} \cdot$ Kumpei Tanisawa $^{43}$. Jane Seto ${ }^{44,45}$. Kathryn North ${ }^{44,45}$. Siddhartha S. Angadi ${ }^{46}$. Maria Jose Martinez-Patiño $0^{47}$. Mats Borjesson ${ }^{7,48,49} \cdot$ Luigi Di Luigi $^{7,50}$. Michiko Dohi ${ }^{7,51}$. Jeroen Swart ${ }^{7,52}$. James Lee John Bilzon ${ }^{7,53}$ (1) - Victoriya Badtieva ${ }^{7,54,55}$ (I) Irina Zelenkova ${ }^{17}$. Juergen M. Steinacker ${ }^{6,7,56}$ (1) Norbert Bachl ${ }^{6,7,57,58} \cdot$ Fabio Pigozzi $^{4,6,7,11}$ (1) $\cdot$ Michael Geistlinger ${ }^{7,59}$. Dimitrios G. Goulis ${ }^{60}$ (D) . Fergus Guppy ${ }^{2,61}$ (D) Nick Webborn ${ }^{62} \cdot$ Bulent O. Yildiz $^{63}$ (D) $\cdot$ Mike Miller $^{64}$. Patrick Singleton $^{64} \cdot$ Yannis P. Pitsiladis ${ }^{1,2,4,6,7}$ (])

Yannis P. Pitsiladis

Y.Pitsiladis@brighton.ac.uk

1 Centre for Exercise Sciences and Sports Medicine, FIMS Collaborating Centre of Sports Medicine, Rome, Italy

2 Centre for Stress and Age-Related Disease, University of Brighton, Brighton, UK

3 The Gender Identity Clinic Tavistock and Portman NHS Foundation Trust, London, UK

4 Department of Movement, Human and Health Sciences, University of Rome "Foro Italico", Rome, Italy

5 Union Cycliste Internationale (UCI), Aigle, Switzerland

6 European Federation of Sports Medicine Associations (EFSMA), Lausanne, Switzerland

7 International Federation of Sports Medicine (FIMS), Lausanne, Switzerland

8 British Association Sport and Exercise Medicine, Doncaster, UK

9 British Cycling and University of Liverpool, Liverpool, UK

10 Department of Pneumology, Pulmonary Function Laboratory, Medicine Clinic (KIMII), University of Vienna, Vienna, Austria

11 Villa Stuart Sport Clinic, FIFA Medical Center of Excellence, Rome, Italy

12 Italian Federation of Sports Medicine (FMSI), Rome, Italy

13 Centre for Exercise Science and Sports Medicine, University of the Witwatersrand, Johannesburg, South Africa

14 Department of Sports Medicine, Humboldt University and Charité University School of Medicine, Berlin, Germany

15 Department of Cardiology, University Hospital Zurich, University Heart Centre, University of Zurich, Zurich, Switzerland

16 Division of Exercise Science and Sports Medicine, University of Cape Town, Cape Town, South Africa
17 GENUD Research Group, FIMS Collaborating Center of Sports Medicine, Department of Physiatry and Nursing, University of Zaragoza, Zaragoza, Spain

18 Orthopaedic Center Theresie, Munich, Germany

19 Department of Sport and Social Sciences, Norwegian School of Sport Sciences, Oslo, Norway

20 Centre of Research and Innovation for Sport, Technology and Law (CRISTAL), De Montfort University, Leicester, UK

21 Sporting Integrity Ltd, Stoke Mandeville, UK

22 Department of Sports Medicine, San Antonio Catholic University of Murcia, Murcia, Spain

23 FIMS Collaborating Center of Sports Medicine, Guadalajara, Mexico

24 Department of Orthopaedics, University of São Paulo Medical School, São Paulo, Brazil

25 Interbalkan Medical Center, FIMS Collaborating Center of Sports Medicine, Thessaloniki, Greece

26 Department of Anatomy and Surgical Anatomy, Faculty of Health Sciences, School of Medicine, Aristotle University of Thessaloniki, Thessaloniki, Greece

27 Amsterdam Collaboration on Health and Safety in Sports, Department of Public and Occupational Health, Amsterdam UMC, Vrije Universiteit Amsterdam, Amsterdam Movement Sciences, Amsterdam, The Netherlands

28 Department of Family Medicine and Community Health, University of Minnesota, Minneapolis, USA

29 Biomedical Institute, Fluminense Federal University Medical School, Niterói, Brazil

30 Universidade Federal do Rio Grande do Sul, Endocrine Unit, Hospital de Clinicas de Porto Alegre, Porto Alegre, Brazil

31 Gloria Sports Arena, FIMS Collaborating Centre of Sports Medicine, Antalya, Turkey

32 Puerto Rico Sports Medicine Federation, San Juan, Puerto Rico 
33 Asian Federation of Sports Medicine (AFSM), Hong Kong Center of Sports Medicine and Sports Science, Hong Kong, China

34 Section Sports Medicine, Faculty of Health Sciences, University of Pretoria, Pretoria, South Africa

35 FIMS Collaboration Centre of Sports Medicine, Sports laboratory, Riga, Latvia

36 FIMS Collaboration Centre of Sports Medicine, Instituto de Medicina do Esporte, Porto Alegre, Brazil

37 Defence Medical Rehabilitation Centre, Stanford Hall, Loughborough, UK

38 Centre for Sports and Exercise Medicine, Queen Mary University of London, London, UK

39 School of Engineering and Materials Science, Queen Mary University of London, London, UK

School of Sport, Exercise and Health Sciences, Loughborough University, Loughborough, UK

41 University Hospital Southampton, Southampton, UK

42 Brighton and Sussex University Hospitals, Brighton, UK

43 Faculty of Sport Sciences, Waseda University, Tokorozawa, Japan

44 Murdoch Children's Research Institute, Melbourne, VIC, Australia

45 Department of Paediatrics, University of Melbourne, The Royal Children's Hospital, Melbourne, VIC, Australia

46 Department of Kinesiology, School of Education and Human Development, University of Virginia, Charlottesville, VA, USA

47 Faculty of Educational Sciences and Sports, University of Vigo, Galicia, Spain

48 Department of Molecular and Clinical Medicine, Sahlgrenska Academy, Center for Health and Performance, Goteborg University, Göteborg, Sweden

49 Sahlgrenska University Hospital/Ostra, Region of Western Sweden, Göteborg, Sweden
50 Unit of Endocrinology, Department of Movement, Human and Health Sciences, University of Rome "Foro Italico", Rome, Italy

51 Sport Medical Center, Japan Institute of Sports Sciences, Tokyo, Japan

52 UCT Research Unit for Exercise Science and Sports Medicine, Cape Town, South Africa

53 Department for Health, University of Bath, Bath, UK

54 I.M. Sechenov First Moscow State Medical University (Sechenov University), Ministry of Health of Russia, Moscow, Russian Federation

55 Moscow Research and Practical Center for Medical Rehabilitation, Restorative and Sports Medicine, Moscow Healthcare Department, Moscow, Russian Federation

56 Division of Sports and Rehabilitation Medicine, Ulm University Hospital, Ulm, Germany

57 Institute of Sports Science, University of Vienna, Vienna, Austria

58 Austrian Institute of Sports Medicine, Vienna, Austria

59 Unit of International Law, Department of Constitutional, International and European Law, University of Salzburg, Salzburg, Salzburg, Austria

60 Unit of Reproductive Endocrinology, 1st Department of Obstetrics and Gynecology, Medical School, Aristotle University of Thessaloniki, Thessaloniki, Greece

61 School of Pharmacy and Biomolecular Sciences, University of Brighton, Brighton, UK

62 School of Sport and Service Management, University of Brighton, Eastbourne, UK

63 Division of Endocrinology and Metabolism, Department of Internal Medicine, Hacettepe University School of Medicine, 06100 Ankara, Turkey

64 World Olympian Association, Lausanne, Switzerland

65 Sport and Exercise Science and Sports Medicine Research and Enterprise Group, University of Brighton, Brighton, UK 